\title{
Age sequences of the elderly' social network and its efficacies on well-being: an urban-rural comparison in China
}

\author{
Zhenhua Zheng ${ }^{1}$ and Hong Chen ${ }^{2^{*}}$ (D)
}

\begin{abstract}
Background: Although social network is a known determinant of the elderly's well-being, it is not clear, in urbanrural and age-comparison, what its structural characteristics are and how it works for well-being. The research aims to discuss the features of the elderly's social network and the social network efficacies on the well-being of older adults in China's urban and rural areas as well as revealing the urban-rural disparities among the elderly of different age groups.
\end{abstract}

Methods: In this study, descriptive statistical analysis and structural equation Modeling (SEM) were used to make a group comparison between the urban and rural elderly of different age groups. All data are quoted from 2014 China Longitudinal Aging Social Survey (CLASS). The survey adopted the multi-stage probability sampling method, targeting Chinese senior citizens aged 60 and above, the ultimate samples totaled 11,511.

Results: The social network of the elderly in China feature a "reverse structure" in age sequences: with ageing, family network of the elderly expand while their friend network shrink; also, the expansion scale of the rural elderly's family network is significantly larger than that of the city's while the shrinkage scale of their friend network is smaller compared with its urban counterpart. The effect of family network on the rural elderly's well-being shows a remarkable increase with age. However, there is no noticeable change in urban elderly groups of different ages.

Conclusion: The social network characteristics of the Chinese elderly are different between different age stages. Namely, the family network and the friend network have the "reverse structure "in age sequences. Meanwhile, the family network and the friend network have different efficacies on the well-being of the elderly in China, and the differences between urban and rural areas are even more obvious. For rural elderly, family network has very important effects on their well-being. Moreover, With the increase of age, family network's efficacies increase gradually. For urban elderly, comparatively, family network is just as important as friend network.

Keywords: Social network, Age sequence, Family network, Friend network, Well-being

\footnotetext{
* Correspondence: ch_jhxy@scu.edu.cn

${ }^{2}$ College of Architecture \& Environment, Sichuan University, No.24 First South Section First Ring Road, Chengdu 610065, China

Full list of author information is available at the end of the article
}

(C) The Author(s). 2020 Open Access This article is licensed under a Creative Commons Attribution 4.0 International License, which permits use, sharing, adaptation, distribution and reproduction in any medium or format, as long as you give appropriate credit to the original author(s) and the source, provide a link to the Creative Commons licence, and indicate if changes were made. The images or other third party material in this article are included in the article's Creative Commons licence, unless indicated otherwise in a credit line to the material. If material is not included in the article's Creative Commons licence and your intended use is not permitted by statutory regulation or exceeds the permitted use, you will need to obtain permission directly from the copyright holder. To view a copy of this licence, visit http://creativecommons.org/licenses/by/4.0/ The Creative Commons Public Domain Dedication waiver (http://creativecommons.org/publicdomain/zero/1.0/) applies to the data made available in this article, unless otherwise stated in a credit line to the data. 


\section{Background}

The socializing and social network of older adults have long been one of the major concerns of the international community $[1,2]$. With the changes of their social roles and the decline in physiological functions, the elderly are often confronted with the problems of negative feelings and illnesses. Compared with young people, they need more support from social network to meet their physical, social, and emotional needs [3, 4].

Existing research on older adults' social network mainly involves two aspects: characteristics and efficacies on well-being. Research on characteristics reveals two different points of views. One is that senior citizens' social network scale is relatively small and will be smaller with aging [5-7]. The other claims that although their friend network may narrow down, their family network tend to expand $[3,8]$. So far, no agreement has been reached regarding social network's efficacies on older adults' well-being. Most scholars are inclined to agree that social network can greatly promote the well-being of the elderly groups [9-13]. However, some scholars have obtained different conclusions. Fuller-Iglesias \& Antonucci (2016) [14] pointed out that the scale of social network doesn't significantly improve the life satisfaction of the elderly. The impact of social network on the wellbeing of the elderly depends on the specific social support it can provide $[15,16]$ or on the network structure and the quality of interpersonal relationships [17-19].

Based on the summary of the existing research, there is no consist conclusion on the characteristics of the elderly's social network or the efficacies of the social network on their well-being. This is due to three reasons: the structural complexity of social network, the heterogeneity of groups of older adults, and the different sources of data. First, for elderly people, their social network are established mainly in two dimensions: family and friend [20, 21 ], which have remarkable differences in terms of ways of communication, emotional connotations, mechanisms of efficacies on well-being, etc. [8, 22]. Some scholars have pointed out that family network have a stronger effect on the well-being of the elderly [23], but others have found that friend network play a greater role under certain circumstances [17, 24]. Therefore, deviations in research conclusions will be inevitably produced if the social network is considered as a whole research objective. Second, due to the noticeable heterogeneity in different elderly groups, the physical and psychological conditions of elderly people at different ages would vary, ignoring the age differences in research may cause deviations in information and conclusion [25-28]. In addition, the characteristics of social network formed by different social backgrounds and cultural traditions are different. Therefore, data of the sample from different regions also could lead to differences in research results $[29,30]$.
This study focused on the elderly in China. Though China's economy is getting tightly connected with the world, it has unique in terms of pension models, family relationships, and cultural background. As Chinese culture is rooted in Confucian values, Chinese families are more like a "community" [31]. The elderly in China are highly dependent on their family members, especially on their children. In addition, the elderly samples of China also have differences between urban and rural area [32, 33]. On the one hand, the economic development of Chinese cities is significantly faster than that of rural areas. The income level and quality of life of urban elderly are also higher than those of rural elderly [34]. On the other hand, there are differences in the implementation of the family planning system in urban and rural areas. The family planning policy is strictly implemented in cities, and a couple can only have one child. However, in many rural areas, the one-and-a-half child policy has long been adopted, which means that if the first child of a couple is a girl, they can have a second child. Therefore, in China, a country with distinctive characteristics of urban-rural dual structure, there must be differences in the structural characteristics of the elderly's social network, as well as in the mechanisms of their efficacies on well-being of the urban and rural areas. However, the existing literatures lack comparative studies in terms of different dimensions of the social network, different age stages of the elderly, and the difference between the Chinese urban and rural areas.

Our study compared multiple groups of elderly people in China. The research objectives include the following aspects: (1) Through the comparison among different age stages, reveal the characteristics of the social network of the elderly in China urban and rural areas; (2) To compare the efficacies of social network in different dimensions on the well-being of the elderly in China; (3) To compare the efficacies of social network on the wellbeing of urban-rural elderly in different age stages. Our study is expected to: theoretically enrich the research content on the characteristics of the elderly's social network and its efficacies on well-being with the research conclusions from Chinese samples. Moreover, in respect of practice, our conclusions provide a reference for the formulation of public policy for the elderly in China and help promote the development of active ageing.

\section{Methods}

\section{Study population}

All data in this article are quoted from 2014 China Longitudinal Aging Social Survey (CLASS). The survey was conducted by Chinese Investigation and Statistics Center of Renmin University of China from June 1 to August 31, 2014. The Academic Committee of the School of Statistics of Renmin University of China is responsible 
for the ethical approval of the survey data and related issues. It aims to collect the data regularly and systematically about the socio-economic backgrounds and the situation of children of Chinese elderly in order to find out a variety of problems that they have to face when aging. It is thus expected to provide statistical basis for the study of aging in China and the solution to this issue. The CLASS (2014) survey adopted the multi-stage probability sampling method. The Primary Sampling Units (PSU) were selected at county-level areas, including counties, county-level cities, and districts, and village / neighborhood committees were selected as the Secondary Sampling Units (SSU). Map sampling was used in each SSU to obtain survey samples. The survey targets are Chinese citizens aged 60 and above (no age limit) living in the current address. The survey was conducted in the form of face-to-face interviews and reading questionnaires. That is, the interviewer reads the questions and answers one by one according to the questionnaire, the interviewee selects the corresponding answer item, and then the interviewer records them on the questionnaire. The survey covers 29 provinces, autonomous regions, municipalities in China. The final sample includes 134 counties, districts, and 462 villages with a total of 11,511 people.

Internationally those of 60 or 65 are generally regarded as senior citizens. In China, the academic community tends to agree that the elderly can be divided into three tiers based on their actual age $[35,36]$, that is, the young-old (60-69), the middle-old (70-79), and the oldold $(80+)$. We therefore divided our subjects accordingly into these three categories. The valid urban samples turned out to include 3565 young-old subjects, 2200 middle-old subjects, and 1142 old-old subjects. For the valid rural samples, the numbers were respectively 2451 , 1440, and 713.

\section{Measurement of social network}

Social network refers to a collection of specific individuals and the various relationships that connect them (such as friendship, communication, and the offer of advice) [37]. For the elderly, the intimate relationship with families and friends count more as their working and social functions decline [3]. Regarding social network measurement, Lubben Social Network Scale 6 (LSNS-6) designed by Lubben et al. (2006) [21] has been widely acknowledged $[8,38]$. CLASS also used this scale in its survey to collect the data of older adults' social network. The scale includes 6 indicators in two categories of family network and friend network. The former includes 3 indicators of family contacts, family talks, and family supports, and the latter comprises 3 indicators of friend contacts, friend talks, and friend supports. The description of each variable measurement is shown in Table 1.

Table 1 Measurement of social network and older adults' well-being

\begin{tabular}{|c|c|c|c|c|}
\hline \multicolumn{2}{|l|}{ Latent variables } & \multirow{2}{*}{$\begin{array}{l}\text { Observed variables } \\
\text { Family contacts }\end{array}$} & \multirow{2}{*}{$\begin{array}{l}\text { Problems } \\
\text { How many family members/ } \\
\text { relatives do you see or hear } \\
\text { from at least once a month? }\end{array}$} & \multirow{2}{*}{$\begin{array}{l}\text { Values } \\
0=\text { none, } 1=1,2=2,3=3-4,4=5-8,5=9 \\
\text { and above }\end{array}$} \\
\hline $\begin{array}{l}\text { Independent variable: } \\
\text { Social network }\end{array}$ & Family network & & & \\
\hline & & Family talks & $\begin{array}{l}\text { How many family members/ } \\
\text { relatives do you feel at ease } \\
\text { with that you can talk about } \\
\text { private matters? }\end{array}$ & $\begin{array}{l}0=\text { none }, 1=1,2=2,3=3-4,4=5-8,5=9 \\
\text { and above }\end{array}$ \\
\hline & & Family supports & $\begin{array}{l}\text { How many family members/ } \\
\text { relatives do you feel close to } \\
\text { such that you could call on } \\
\text { them for help? }\end{array}$ & $\begin{array}{l}0=\text { none, } 1=1,2=2,3=3-4,4=5-8,5=9 \\
\text { and above }\end{array}$ \\
\hline & Friend network & Friend contacts & $\begin{array}{l}\text { How many friends do you see or } \\
\text { hear from at least once a month? }\end{array}$ & $\begin{array}{l}0=\text { none, } 1=1,2=2,3=3-4,4=5-8,5=9 \\
\text { and above }\end{array}$ \\
\hline & & Friend talks & $\begin{array}{l}\text { How many family members/ } \\
\text { relatives do you feel at ease } \\
\text { with that you can talk about } \\
\text { private matters? }\end{array}$ & $\begin{array}{l}0=\text { none, } 1=1,2=2,3=3-4,4=5-8,5=9 \\
\text { and above }\end{array}$ \\
\hline & & Friend supports & $\begin{array}{l}\text { How many family members/ } \\
\text { relatives do you feel close to } \\
\text { such that you could call on } \\
\text { them for help? }\end{array}$ & $\begin{array}{l}0=\text { none, } 1=1,2=2,3=3-4,4=5-8,5=9 \\
\text { and above }\end{array}$ \\
\hline \multirow{2}{*}{\multicolumn{2}{|c|}{$\begin{array}{l}\text { Dependent variables: older } \\
\text { adults' well-being }\end{array}$}} & life satisfaction & $\begin{array}{l}\text { Overall, are you satisfied with } \\
\text { your current life? }\end{array}$ & $\begin{array}{l}1=\text { very unsatisfied, } 2=\text { quite } \\
\text { unsatisfied, } 3=\text { average, } 4=\text { quite } \\
\text { satisfied, } 5=\text { very satisfied }\end{array}$ \\
\hline & & Self-rated health & $\begin{array}{l}\text { How do you think of your } \\
\text { current health condition? }\end{array}$ & $\begin{array}{l}1=\text { very unhealthy, } 2=\text { quite } \\
\text { unhealthy, } 3=\text { average, } 4=\text { quite } \\
\text { healthy, } 5=\text { very healthy }\end{array}$ \\
\hline
\end{tabular}




\section{Measurement of well-being}

Well-being takes place in the realm of human psychology and spirit, which is a sense of happiness and benefits obtained via subjective judgment and feelings [39]. In early studies of psychology and sociology, well-being was a general concept based on the measurement of 3 indicators - life satisfaction, positive feelings, negative feelings [40]. In later pertinent studies, indicators used by researchers in the measurement of well-being have varied to some extent. For example, Nguyen et al. (2016) [23] refer to the three indicators of life satisfaction, happiness, and self-esteem; Fuller-Iglesias \& Antonucci (2016) [14] used life satisfaction, self-rated health, depressive symptoms and chronic health conditions in measurement. No matter which indicators researchers may turn to, what they have in common is that the indicators are centered on life satisfaction and subjective judgment, in which life satisfaction has remained a core measuring variable as it can best manifest individual life quality. However, for the elderly in particular, the significance of health has far surpassed everything else. The self-rated health of the elderly not only includes the comprehensive evaluation of their physical health, but also reflects the information on their psychological status [41]. Self-rated health of the elderly is a more comprehensive psychological measurement index [42]. Therefore, this research refers to life satisfaction and self-rated health as measuring indicators of older adults' well-being.

\section{Control variables}

This article included age, gender, number of children, marital status, income and education into the model as control variables. Gender and marital status are twocategory variables, and marital status is divided into two categories: spouse and non-spouse. Income measures the total sum of the personal income of older adults in the past year and in this article income is measured on 5 tiers. This is because income data often are rough numbers when they are obtained, and what's between income and well-being is not a simple linear relationship. Therefore, it is not meaningful to study how much health is improved with the increase of certain amount of income. Only by comparing well-being of different income groups can it better promote policy-making and ensure its implementation [43]. That explains why most sociologists would stratify income data in their research [44, 45]. The values of older adults' income level in this article are classified according to the 20, 40, 60 and $80 \%$ quantiles of the total sample income value of the CLASS data. The final values are ranked from low to high as: 2000 Chinese Yuan (CHY) and below is low-income level with the value of $1 ; 2001-7200 \mathrm{CHY}$ is lowermiddle income level with the value of 2; 7201-20,000
CHY is middle-income level with the value of 3; 20,001$32,164 \mathrm{CHY}$ is upper-middle income level with the value of 4; 32,164 CHY and above is high-income level with the value of 5 . Education was measured on a six-point scale, with scores ranging from low to high as: $1=$ illiterate; 2 = private schooling or literacy class; $3=$ primary school; $4=$ junior high school; $5=$ senior high school or vocational school; $6=$ junior college and above.

\section{Statistical analyses}

This research adopted descriptive statistical analyses and structure equation model (SEM) to analyze the data. Structural equation model analysis method has more advantages when dealing with the aggregate problems of measured variables and group comparison. Therefore, this paper uses SEM method to analyze the complex logical relationship between social network and the wellbeing of urban and rural elderly at different ages. In order to test whether the data fit the SEM analysis, we grouped all observed variables with 27 and 73 quartiles as critical values and performed a t-test. The results showed all variables are highly discriminative and are suitable for SEM analysis.

Multi-factor confirmatory analysis was performed on three measurement models of family network, friend network, and older adults' well-being. The factor loading of all observation variables exceeds 0.5 , and the reliability coefficient (SMC) is more than 0.25. All measurement models (CFA) have good reliability and validity, and are appropriate for SEM analysis.

The concept model was fitted based on the CLASS data. The output results show that the fitness indexes GFI and TLI failed to meet the standards, so the model needs to be optimized. The output of the model fitting shows that the value of correction index between the residua of "friends talking" and the residual of "relatives talking" is the largest. Therefore, after the correlation between the two is established, the model is re-fitted, and the result of GFI and TLI all meet the ideal standards. Meanwhile, RMSEA, $\mathrm{X}^{2}$, and DF have been further optimized, so the optimized model has a good fitness. (Table 2).

\section{Results}

\section{Descriptive statistics}

The descriptive statistics of the main variables are shown in Table 3. From the mean of total sample of the social

Table 2 Comparison of fit index before and after model optimization

\begin{tabular}{llllll}
\hline & GFI & TLI & $\mathbf{X}^{\mathbf{2}}$ & DF & RMSEA \\
\hline Pre-optimization model & 0.890 & 0.859 & 1048 & 59 & 0.069 \\
Optimized model & 0.927 & 0.904 & 719 & 58 & 0.057 \\
Ideal standard & $>0.9$ & $>0.9$ & - & - & $<0.08$ \\
\hline
\end{tabular}


Table 3 Descriptive statistics

\begin{tabular}{|c|c|c|c|c|c|c|c|c|c|}
\hline \multicolumn{2}{|c|}{ Latent variables } & \multirow{2}{*}{$\begin{array}{l}\text { Observed } \\
\text { variables }\end{array}$} & \multirow{2}{*}{$\begin{array}{l}\text { Mean of } \\
\text { total sample }\end{array}$} & \multicolumn{3}{|c|}{ Mean of city sample } & \multicolumn{3}{|c|}{ Mean of rural sample } \\
\hline & & & & $\begin{array}{l}\text { The Young- } \\
\text { old group }\end{array}$ & $\begin{array}{l}\text { The Middle- } \\
\text { old group }\end{array}$ & $\begin{array}{l}\text { The Old- } \\
\text { old group }\end{array}$ & $\begin{array}{l}\text { The Young- } \\
\text { old group }\end{array}$ & $\begin{array}{l}\text { The Middle- } \\
\text { old group }\end{array}$ & $\begin{array}{l}\text { The Old- } \\
\text { old group }\end{array}$ \\
\hline \multirow[t]{6}{*}{ Social network } & Family network & Family contacts & 3.23 & 3.25 & 3.29 & 3.29 & 3.12 & 3.18 & 3.36 \\
\hline & & Family talks & 2.26 & 2.29 & 2.29 & 2.31 & 2.20 & 2.24 & 2.10 \\
\hline & & Family supports & 3.02 & 2.94 & 3.04 & 3.18 & 2.95 & 3.10 & 3.21 \\
\hline & Friend network & Friend contacts & 2.58 & 2.86 & 2.63 & 2.14 & 2.62 & 2.35 & 2.00 \\
\hline & & Friend talks & 1.59 & 1.84 & 1.60 & 1.37 & 1.55 & 1.43 & 1.17 \\
\hline & & Friend supports & 1.79 & 2.10 & 1.72 & 1.44 & 1.81 & 1.59 & 1.26 \\
\hline \multirow{2}{*}{\multicolumn{2}{|c|}{ Older adults' well-being }} & Life satisfaction & 4.01 & 4.00 & 4.13 & 4.15 & 3.93 & 4.03 & 3.99 \\
\hline & & Self-rated health & 3.20 & 3.46 & 3.21 & 3.13 & 3.10 & 2.94 & 2.93 \\
\hline \multirow{6}{*}{\multicolumn{2}{|c|}{ Control variables }} & Income & 2.88 & 3.49 & 3.48 & 3.50 & 2.16 & 1.82 & 1.67 \\
\hline & & Education & 2.91 & 3.61 & 3.31 & 2.67 & 2.5 & 2.09 & 1.64 \\
\hline & & Gender & 0.52 & 0.50 & 0.55 & 0.56 & 0.48 & 0.54 & 0.58 \\
\hline & & Age & 70.31 & 63.76 & 74.35 & 83.84 & 63.78 & 74.20 & 83.58 \\
\hline & & $\begin{array}{l}\text { Number of } \\
\text { children }\end{array}$ & 3.09 & 2.10 & 3.28 & 3.93 & 2.83 & 4.13 & 4.88 \\
\hline & & Marital status & 0.35 & 0.20 & 0.40 & 0.64 & 0.22 & 0.48 & 0.76 \\
\hline
\end{tabular}

network, the mean values of the observed variables of the family network (family contacts, family talks, and family supports) are respectively 3.23, 2.26, and 3.02. Correspondingly, the mean values of the observed variables of the friend network (family contact, family talk, family support) are $2.58,1.59,1.79$, respectively. Obviously, the mean values of family network are larger than those of the friend network. Through the comparison of urban and rural samples, it can be found that the difference in the mean of family network' s observed variables is not obvious. However, regarding the mean of friend network's observed variables, the values of rural sample are generally lower than those of urban sample. From the mean of total sample of the older adults' well-being, life satisfaction is higher than self-rated health. Meanwhile, remarkably, life satisfaction and Self-rated health of rural elderly are both lower than that of urban elderly.

In the control variables, the mean values of the total sample of income and education are 2.88 and 2.91, respectively. Moreover, the mean of each group of the urban sample is significantly higher than that of the rural. Regarding gender structure, $52 \%$ of the total sample are female and $48 \%$ are male. The gender ratio of the elderly in urban and rural areas is relatively balanced.
The mean value of age' total sample is 70.31 , which is basically the same between urban and rural areas. The mean of the number of children in total sample is 3.09, that is, about three children per elderly Chinese family. The older the group samples are, the more children they have. The number of children in rural sample is significantly higher than that in urban. The mean value of the total sample for marital status is 0.35 , meaning that $65 \%$ of the elderly are accompanied by a spouse, and the proportion of urban and rural elderly with spouses have gradually decreased with age.

\section{Structural characteristics: the urban-rural differences in age sequences in terms of older adults' social networks and their well-being}

We summed the latent variables of each group sample and compared them. Therefore, it can clearly reveal the changing trends of social network and older adults' wellbeing at different ages in urban and rural China. Table 4 showed the mean values of latent variables, including family network, friend network and older adults' wellbeing, at different age groups in urban and rural China. The statistical results of the difference comparison were shown in Fig. 1.

Table 4 The mean comparison of family network, friend network and well-being of the urban-rural elderly in different age groups

\begin{tabular}{|c|c|c|c|c|c|c|c|c|c|}
\hline & \multicolumn{3}{|c|}{ Family network } & \multicolumn{3}{|c|}{ Friend network } & \multicolumn{3}{|c|}{ Older adults' well-being } \\
\hline & $\begin{array}{l}\text { The young- } \\
\text { old group }\end{array}$ & $\begin{array}{l}\text { The middle- } \\
\text { old group }\end{array}$ & $\begin{array}{l}\text { The old- } \\
\text { old group }\end{array}$ & $\begin{array}{l}\text { The young- } \\
\text { old group }\end{array}$ & $\begin{array}{l}\text { The middle- } \\
\text { old group }\end{array}$ & $\begin{array}{l}\text { The old- } \\
\text { old group }\end{array}$ & $\begin{array}{l}\text { The young- } \\
\text { old group }\end{array}$ & $\begin{array}{l}\text { The middle- } \\
\text { old group }\end{array}$ & $\begin{array}{l}\text { The old- } \\
\text { old group }\end{array}$ \\
\hline Urban & 8.48 & 8.62 & 8.78 & 6.8 & 5.95 & 4.95 & 7.46 & 7.34 & 7.28 \\
\hline Rural & 8.27 & 8.52 & 8.67 & 5.98 & 5.37 & 4.43 & 7.03 & 6.97 & 6.92 \\
\hline
\end{tabular}




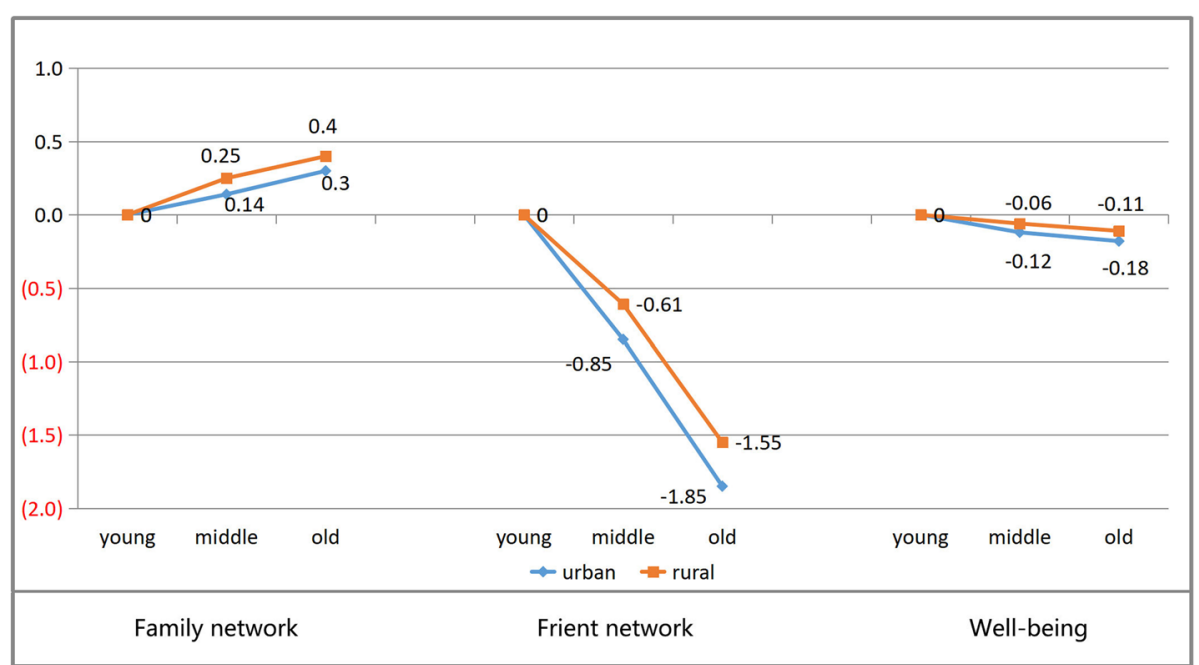

Fig. 1 The comparison of family network, friend network and well-being between urban-rural elderly in different ages

With the increase of age, the gaps of urban and rural family network tend to be widened: for urban groups, the family network's mean value of the middle-old is 0.14 more than that of the young-old, and the mean value of the old-old is 0.30 more than that of the young-old; for rural groups, the family network's mean value of the middle-old is 0.25 more than that of the young-old, and that of the old-old is 0.40 more than that of the young-old. On the other hand, with the increase of age, the friend network of the elderly in urban and rural areas were gradually reduced: for urban groups, the average friend network's mean value of the middle-old is 0.85 lower than that of the young-old, and that of the old-old is 1.85 lower than that of the young-old; for rural groups, the friend network's mean value of the middle-old is 0.61 lower than that of the young-old, and the mean value of the old-old is 1.55 lower than that of the young-old.

Meanwhile, the older adults' well-being in urban and rural areas dropped slightly as they grow older. For urban groups, the mean value of well-being of the middle-old is 0.12 lower than that of the young-old, and the old-old is 0.18 lower than that of the young-old. In comparison, the decline in well-being of rural elderly is smaller than that of urban elderly: The mean of the middle-old is only 0.06 lower than that of the young-old, and the mean of the old-old is only 0.11 lower than that of young-old.

\section{Mechanism of well-being efficacy: an urban-rural comparison of how social network influence well-being of the elderly at different ages}

We have made groups comparison of the models in three age stage groups of urban-rural elderly, separately. The results showed: $P$ value of the rural group comparison is $0.026<0.05$; $p$ value of the urban group comparison is $0.082>0.05$. These results indicated that there is significant difference in rural group, but not in urban group. The comparison of group model fitting results was shown in Table 5, and the standardized path was shown in Fig. 2.

There were obvious differences between the influence of family network and friend network on the older adults' well-being. First, family network greatly enhance the well-being of all urban and rural elderly groups. From younger to older groups, the total effect values of urban elderly's well-being affected by family network are $0.240(P=0.000), 0.165(P=0.001)$ and $0.221^{* * *}(P=$ $0.001)$. Correspondingly, from younger to older groups, the figures of the three age groups of rural elderly are respectively $0.243(P=0.000), \quad 0.296(P=0.000)$ and

Table 5 An urban-rural comparison of group model fitting results at different age groups

\begin{tabular}{|c|c|c|c|c|c|c|c|}
\hline \multirow[t]{3}{*}{ Independent variables } & & \multicolumn{6}{|c|}{ Dependent variables: older adults' well-being } \\
\hline & & \multicolumn{3}{|l|}{ Rural elderly } & \multicolumn{3}{|c|}{ Urban elderly } \\
\hline & & $\begin{array}{l}\text { The young- } \\
\text { old group }\end{array}$ & $\begin{array}{l}\text { The middle- } \\
\text { old group }\end{array}$ & $\begin{array}{l}\text { The old- } \\
\text { old group }\end{array}$ & $\begin{array}{l}\text { The young- } \\
\text { old group }\end{array}$ & $\begin{array}{l}\text { The middle- } \\
\text { old group }\end{array}$ & $\begin{array}{l}\text { The old- } \\
\text { old group }\end{array}$ \\
\hline \multirow[t]{2}{*}{ Independent variables: Social network } & Family network & $0.243^{\mathrm{a}}$ & $0.296^{\mathrm{a}}$ & $0.402^{\mathrm{a}}$ & $0.240^{\mathrm{a}}$ & $0.165^{\mathrm{a}}$ & $0.221^{a}$ \\
\hline & Friend network & $0.087^{b}$ & $0.116^{\mathrm{b}}$ & 0.073 & $0.151^{\mathrm{a}}$ & $0.207^{\mathrm{a}}$ & $0.140^{\mathrm{a}}$ \\
\hline
\end{tabular}

Notes: ${ }^{a}$ means significance at the 0.01 confidence level; ${ }^{\mathrm{b}}$ means significance at the 0.05 confidence level 


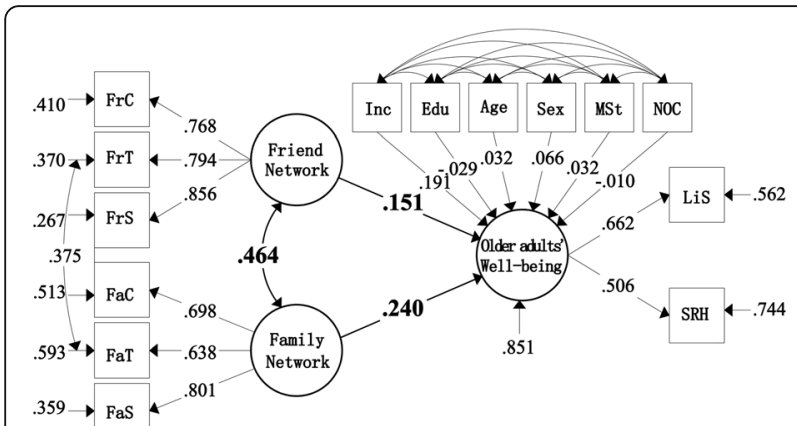

The young-old group in urban areas

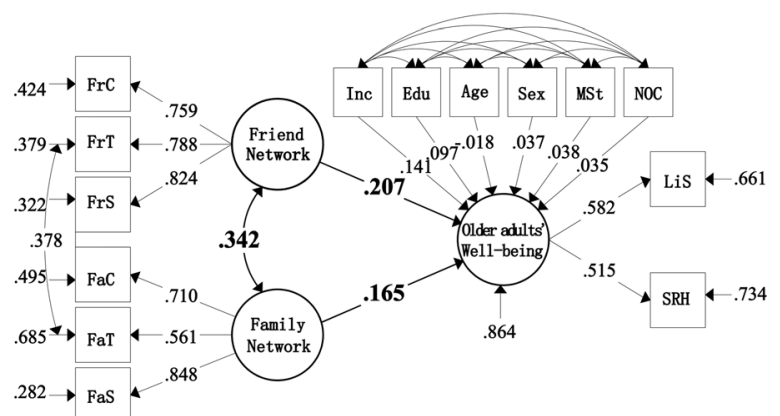

The middle-old group in urban areas

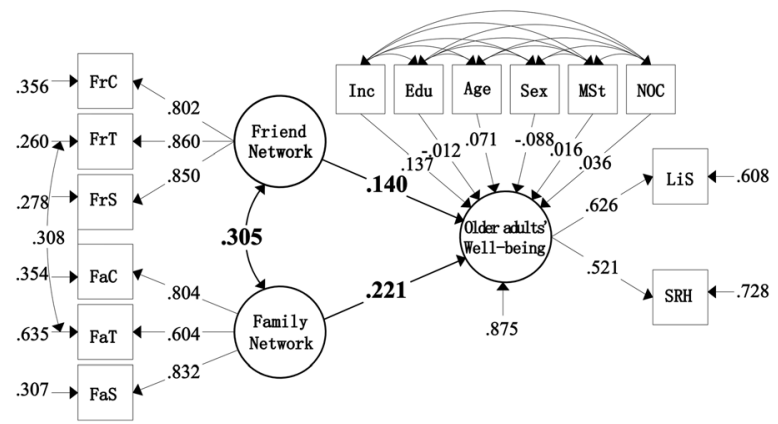

The old-old group in urban areas
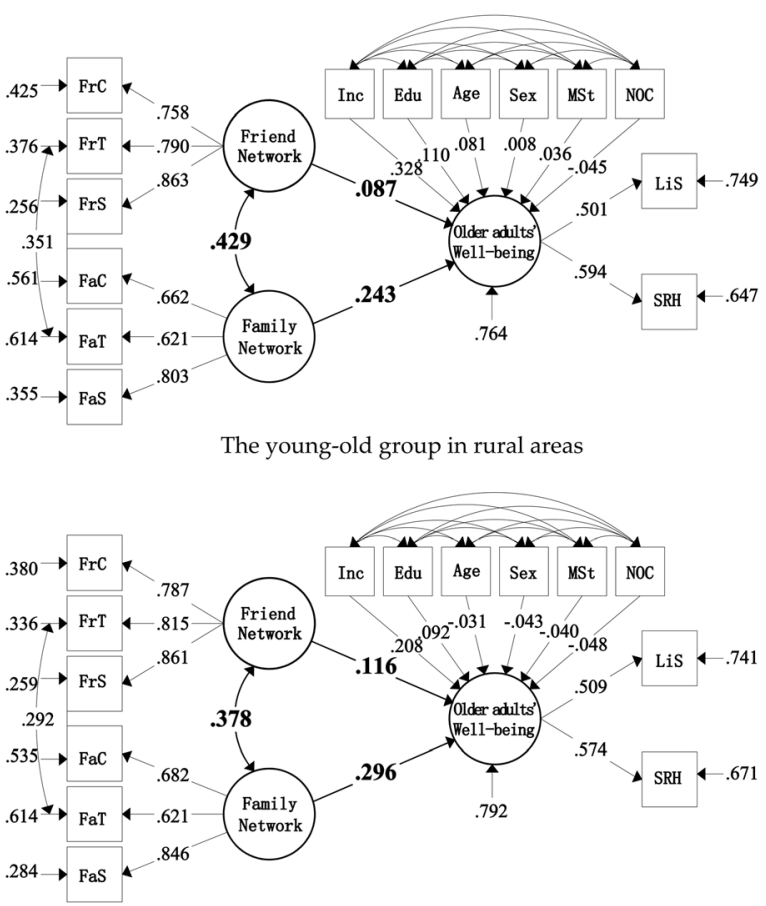

The middle-old group in rural areas

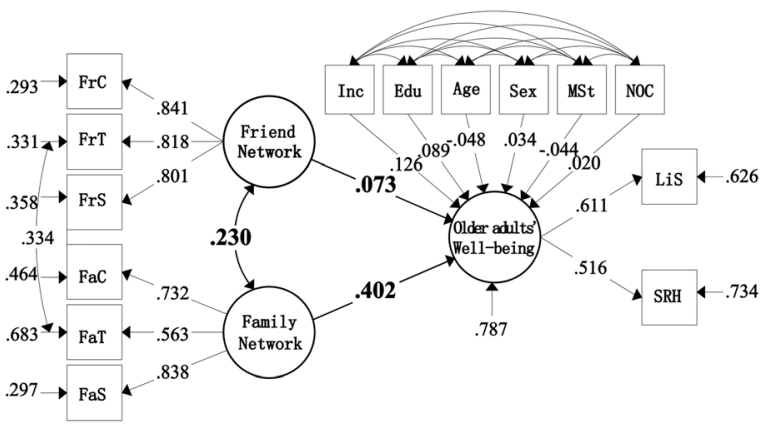

The old-old group in rural areas

Fig. 2 The comparison of standardized path of urban and rural age models

$0.402(P=0.000)$. The effect of family network on the rural elderly's well-being shows a remarkable increase with age. However, the impact on the urban elderly of different age groups has not changed significantly.

Second, the influence of friend network on older adults' well-being varies significantly between urban and rural groups. Friend network have a positive effect for all urban elderly. With increasing age, the effect values are $0.151(P=0.000), 0.207(P=0.000), 0.140(P=0.007)$, respectively. On the other hand, for rural elderly, friend network can only influence the well-being of the youngold and middle-old groups with the effect value of $0.087(P=0.002)$ and $0.116(P=0.012)$, respectively. Its impact on the well-being of the old-old group has no significant effect.

\section{Discussion}

Our study has compared older adults in China's urban and rural areas, and found that the social network and its efficacies on well-being between urban-rural elderly have both shown great differences.

Our research confirms the conclusion of some scholars that there are significant differences in the characteristics of old adult' social network among different age groups [25-28]. In addition, interestingly, we have found some peculiar characteristics of the old adult' social network in China. First, with the increase of age, the structure of the old adults' social network shows a reverse progressive sequence. That is, as the elderly grow old, their family network expand while their friend network shrink gradually. We call this characteristic of the 
old adults' social network as the "reverse structure " in age sequences. Secondly, there are differences between urban and rural elderly in the characteristic of "reverse structure", which are reflected in the two dimensions of family network and friend network. Specifically, the expansion scale of family network of rural elderly with age is significantly greater than that of urban. Correspondingly, the reduction of friend network of rural elderly is smaller than that of urban elderly. Thirdly, the wellbeing of the elderly shows a decreasing trend with age. However, there is a slight difference between urban and rural areas, that is, the decline trend of well-being of rural group is smaller than that of urban group.

We believe that the "reverse structure" characteristic of Chinese elderly's social network can be explained from subjective and objective perspectives. The subjective reason is that as the age increases, the physiological functions of the elderly gradually decline, and more emotional and material support in life are expected from their families. The objective reason is that the fertility status of the older elderly group is not affected by the family planning policy, whose impact on the young-old and the middle-old groups is growing, instead. Inevitably, the number of children from older to younger senior citizens has dropped accordingly, and the family size are bound to shrink in the end.

Our research validated the conclusion that different dimensions of social network have different effects on the older adults' well-being $[8,22,23]$. The view that social network have significant effects on the older adults' well-being at different ages has only been confirmed in the rural group [25-28], but not in the urban group. For the rural elderly, we found that the family network was more important to their well-being than the friend network. Specifically, the family network has a significant influence on the well-being of rural elderly in all age groups, and it gradually increases with age. However, the friend network has a significant influence lightly only on the young-old and middle-old age groups. This conclusion is contrary to the findings of some scholars based on Western elderly samples $[17,24]$. They found that the influence of friend network on the well-being of the elderly was more important than that of family network.

Compared with the rural elderly, the family network has a smaller efficacicy on the well-being of the urban elderly. In fact, for the urban elderly, the friend network and the family network have an equally important efficiency on their well-being. This is a very interesting finding. We believe that the important reason for the different trends in the well-being of urban and rural elderly is the difference in the impact of social network on their well-being.

With the increase of age, the physical functions of older adults gradually decline and they even have to face death. But for the rural elderly, the trend of their wellbeing decline with age is not great. This is because the support from their family network greatly compensates their sense of loss when aging. The family network scale of the rural elderly grows accordingly with age. Meanwhile, family network's efficacies on their well-being are correspondingly increasing. This compensatory support from the family network which grows with age allows progressive enhancement of the well-being of the middle-old and the old-old groups in rural areas. This is the crucial reason that explains why the well-being of rural elderly doesn't decline dramatically with age.

On the other hand, family network had certain positive efficacies on the well-being of urban elderly. However, compared with the rural elderly, family network of the urban elderly was much smaller in terms of both expansion scale and its impact on the well-being. As a result, the compensatory efficacy of family network on the wellbeing of the urban elderly is much smaller. For another, although the friend network played an important role in the well-being of the urban elderly, with the growth of age, their friend network has been greatly shrunk. Due to this negative impact from the shrinking friend network plus the insufficient compensatory efficacy of family network, the decline trend of the urban elderly wellbeing with age was greater than that of the rural elderly.

It needs to be addressed that limitations still exist in this research. First, all statistics quoted are from the 2014 China Longitudinal Aging Social Survey (CLASS) while some social changes have taken place afterwards and so have the elderly groups in different age. Therefore, future discussions should be based on more up-todate statistical information. Secondly, this longitudinal survey conducted the measurement of subjects' social network from two dimensions: family network and friend network. In fact, more detailed dimensions may facilitate in-depth discussions on the issue of old adults' social network, such as adding neighbor network etc. Thirdly, older adults' well-being in this article is based on subjective assessments, i.e., how people feel. Further research regarding social network efficacies on old adults' well-being needs to be done by using objective measurements data.

\section{Conclusion}

As a key to "active aging", the efficacies of social network lie not only in effectively improving older adults' well-being and their life quality. They also positively contribute to the old-age security improvement, alleviating the problems of elderly care in China and promoting the healthy development of the entire country. Based on the large sample of data (CLASS), we found that the social network characteristics of the Chinese elderly are different between different age stages. Namely, the 
family network and the friend network have the "reverse structure " in age sequences. Furthermore, there are obvious urban-rural differences in the impact of social network on the well-being of the Chinese elderly. For the rural elderly, the family network has a strong positive effect on their well-being than the friend network, and the intensity of this effect gradually increases with age. However, for the urban elderly, the impact of family network on their well-being is just as important as that of the friend network.

Considering the differences in the efficacies of social network on the well-being of the elderly in urban and rural areas, it is essential to adopt separate approaches when trying to enhance older adults' well-being in China. To improve the well-being of the rural elderly, attention should be paid to expanding the size of their family network, which can be achieved by expanding the size of the family, encouraging the strengthening of the ties between relatives, etc. Family scale is the basis of family network scale. In current China, with social changes and development, the culture of filial piety and birth rate are naturally weakening or declining. Therefore, we appeal for full liberalization of fertility restrictions, promotion of incentive fertility policies, reduction of economic pressure on youth groups, and improvement of the education system. It is expected that the comprehensive effect in many aspects can bring about the improvement of fertility rate, and then increase the scale of the family. To improve the well-being of the urban elderly, it is equally important to expand scale of their family network and friend network. Therefore, apart from the above-mentioned measures, it is also necessary to pay attention to construct and optimize the environment for socializing, and actively create and cultivate a good atmosphere of social interaction, in order to expand the scale of the friend network of the elderly.

\section{Abbreviations \\ SEM: Structural equation modeling; CLASS: China longitudinal aging social survey; PSU: Primary sampling units; SSU: Secondary sampling units; CHY: Chinese yuan; SMC: Squared multiple correlation; CFA: Confirmatory factor analysis; GFI: Goodness-of-fit index; TLI: Tucker-Lewis index; RMSEA: Root mean square error of approximation; DF: Degree of freedom}

\section{Acknowledgments}

Thanks to Professor Zhenyu Li for his suggestions on manuscript revision.

\section{Authors' contributions}

$\mathrm{ZZ} \& \mathrm{HC}$ conceived and designed the study, and ZZ drafted the original paper. ZZ \& HC performed the statistical analyses. HC contributed to revising the paper and provided further contributions and suggestions. All authors read and approved the final version.

\section{Funding}

The work of ZZ (designing the study, analyzing data and writing the paper) was supported by Humanities and Social Sciences Research Foundation of Ministry of Education of China (Nos. 20YJAZH140).
Availability of data and materials

The population data (CLASS) that support the findings of this study are available from http://class.ruc.edu.cn/

\section{Ethics approval and consent to participate}

The data used in this manuscript were from a large national social survey (CLASS). All the participants provide written consent prior to their participation in the survey, and the research was approved by the Academic Committee of the School of Statistics of Renmin University of China, but the ethics number has not been publicly released.

Consent for publication

Not applicable.

\section{Competing interests}

The authors declare that they have no competing interests.

\section{Author details}

${ }^{1}$ College of Communication and Art Design, University of Shanghai for Science and Technology, No.516, Jungong Road, Shanghai 200093, China. ${ }^{2}$ College of Architecture \& Environment, Sichuan University, No.24 First South Section First Ring Road, Chengdu 610065, China.

Received: 14 January 2020 Accepted: 15 September 2020

Published online: 29 September 2020

\section{References}

1. Howard Litwin. Social networks and well-being: a comparison of older people in Mediterranean and non-Mediterranean countries. J Gerontol 2010; 65B:599-608. https://doi.org/10.1093/geronb/gbp104.

2. Berglund $H$, Hasson $H$, Wilhenlmson $K$, Duner A, Dahlin-Ivanoff S. The impact of socioeconomic conditions, social networks, and health on frail older People's life satisfaction: a cross-sectional study. Health Psychol Res 2016:4:26-31. https://doi.org/https://doi.org/10.4081/hpr.2016.5578.

3. Antonucci T. Social relations: an examination of social networks, social support, and sense of control. In: Birren JE, Schaie KW, editors. Handbook of the psychology of aging. San Diego: Academic Press; 2001. p. 427-53.

4. Bahramnezhad F, Chalik R, Bastani F, Taherpourand M, Navab E. The social network among the elderly and its relationship with quality of life. Electron Physician 2017;9: 4306-4311. https://doi.org/https://doi.org/10.19082/430.

5. Silverman $P$, Hecht $L$, McMillin JD. Modeling life satisfaction among the aged: a comparison of Chinese and Americans. J Cross Cult Gerontol 2000; 15:289-305. https://doi.org/https://doi.org/10.1023/A:1006793304508.

6. Cornwell B, Laumannand EO, Schumm PL. The social connectedness of older adults: a National Profile. Am Sociol Rev 2008;73(2):185-203. https:// doi.org/https://doi.org/10.1177/000312240807300201

7. Cornwell B. Age trends in daily social contact patterns. Res Aging 2011; 33(5):598-631. https://doi.org/https://doi.org/10.1177/0164027511409442.

8. Zang WJ. LiuRP. Determinants of social isolation of the Chinese elderly. Popul Res. 2016;40(5):75-91.

9. Litwin H, Shiovitz-Ezra S. Social network type and subjective well-being in a National Sample of older Americans. The Gerontologist 2011:51(3):379-388. https://doi.org/https://doi.org/10.1093/geront/gnq094.

10. Shouse JN, Rowe SV. Mast BT. Depression and cognitive functioning as predictors of social network size. Clin Gerontol 2013;36(2):147-161. https:// doi.org/https://doi.org/10.1080/07317115.2012.749320.

11. Wang XM. Subjective well-being associated with size of social network and social support of elderly. J Health Psychol 2016;21(6):1037-1042. https://doi. org/https://doi.org/10.1177/1359105314544136.

12. Perkins JM, Subramanian SV, Christakis NA. Social networks and health: a systematic review of sociocentric network studies in low- and middleincome countries. Soc Sci Med 2015;125:60-78. https://doi.org/https://doi. org/10.1016/j.socscimed.2014.08.019.

13. Rafnsson SB, Shankar A, Steptoe A. Longitudinal influences of social network characteristics on subjective well-being of older adults: findings from the ELSA study. J Aging Health 2015;27(5):919-934. https://doi.org/https://doi. org/10.1177/0898264315572111.

14. Fuller-Iglesias HR, Antonucci TC. Familism, social network characteristics, and well-being among older adults in Mexico. J Cross Cult Gerontol 2016;31(1): 1-17. https://doi.org/https://doi.org/10.1007/s10823-015-9278-5. 
15. Vandervoort D. Quality of social support in mental and physical Hhealth Curr Psychol 1999;18(2):205-221. https://doi.org/https://doi.org/10.1007/ s12144-999-1029-8.

16. Lim C, Putnam RD. Religion, social networks, and life satisfaction. Am Sociol Rev 2010;75(6): 914-933. https://doi.org/https://doi.org/10.1177/ 0003122410386686

17. Pinquart M, Sörensen S. Influences of socioeconomic status, social network, and competence on subjective well-being in later life: a meta-analysis. Psychol Aging 2000;15(2):187-224. https://doi.org/https://doi.org/10.1037/ 0882-7974.15.2.187.

18. van der Horst M, Coffe H. How friendship network characteristics influence subjective well-being. Soc Indic Res 2012;107(3):509-529. https://doi.org/ https://doi.org/10.1007/s11205-011-9861-2.

19. Antonucci T, Fiori K, Birditt KS, Jackey L. Convoys of social relations: past present and future. The Handbook of life-span development. 2010. doi: https://doi.org/10.1002/9780470880166.hlsd002012.

20. Guilley E, Pin S, Spini D, d'Epinay CL, Herrmann F, Michel JP. Association between social relationships and survival of Swiss octogenarians. A five-year prospective, population-based study. Aging Clin Exp Res. 2005;17(5):419-25.

21. Lubben J, Blozik E, Gillmann G, Iliffe S, Kruse WV, Beck JC, Stuck AE. Performance of an abbreviated version of the lubben social network scale among three european community-dwelling older adult populations." Gerontologist. 2006;46(4):503-513. https://doi.org/https://doi.org/10.1093/ geront/46.4.503.

22. Giles LC, Anstey KJ, Walker RB, Luszcz MA. Social networks and memory over 15 years of follow up in a cohort of older Australians: results from the Australian longitudinal study of ageing. J Aging Res. 2012; Article ID:856048. https://doi.org/https://doi.org/10.1155/2012/856048.

23. Nguyen AW, Chatters LM, Taylor RJ, Mouzon DM. Social support from family and friends and subjective well-being of older African Americans. J Happiness Stud 2016;17(3):959-979. https://doi.org/https://doi.org/10.1007/ s10902-015-9626-8.

24. Helliwell JF, Putnam RD. The social context of well-being. Philos Trans R Soc Lond B Biol Sci. 2004;359:1435-46.

25. Cooper C, Bebbington P, King M, Jenkins R, Farrell M, Brugha T, McManus S, Stewart R, Livingston G. Happiness across age groups: results from the 2007 National Psychiatric Morbidity Survey. Int J Geriatr Psychiatry 2010;26(6):608614. https://doi.org/https://doi.org/10.1002/gps.2570.

26. Litwin H, Stoeckel KJ. Social networks and subjective wellbeing among older Europeans: does age make a difference? Ageing Soc 2012;33(7):12631281. https://doi.org/https://doi.org/10.1017/S0144686X12000645.

27. Phongsavan P, Grunseit AC, Bauman A, Broom D, Byles Julie, Clarke J, Redman S, Nutbeam, D. age, gender, social contacts, and psychological distress: Fingdings from the 45 and up study. J Aging Health 2013;25(6): 921-943. https://doi.org/https://doi.org/10.1177/0898264313497510.

28. Harling G, Morris KA, Manderson L, Perkins JM, Berkman LF. Age and gender differences in social network composition and social support among older rural south Africans: findings from the HAALSI study. J Gerontol 2020;75: 148-159. https://doi.org/https://doi.org/10.1093/geronb/gby013.

29. Dong $X Q$, Chang ES. Social networks among the older Chinese population in the USA: findings from the PINE study. Gerontology 2017;63(3), 238-252. https://doi.org/https://doi.org/10.1159/000455043.

30. Park NS, Jang, Y, Chiriboga, David A, Chung S. Social network types, health, and well-being of older Asian Americans. Aging Ment Health 2018;23(11): 1569-1577. https://doi.org/https://doi.org/10.1080/13607863.2018.1506751.

31. Zimmer Z, Hermalin Al, Lin HS. Whose education counts? The added impact of adult-child education on physical functioning of older taiwanese. J Gerontol 2002;57(1): S23-S32. https://doi.org/https://doi.org/10.1093/geronb/ 57.1.S23.

32. Chou, Jing-Ann R. Willingness to live in eldercare institutions among older adults in urban and rural China: a nationwide study. Ageing Soc 2010; 30(04):583-608. https://doi.org/https://doi.org/10.1017/S0144686X09990596.

33. Xie E. Pensions and multidimensional elderly poverty and inequality: a comparative perspective on urban and rural non-compulsory pension insurance. Chin J Popul Sci. 2017;5:62-73+127 CNKI:SUN:ZKRK.0.2017-05007.

34. Zhang Y. The analysis on economic development and urban-rural income gap of China. 2012 Fourth International Conference on Multimedia Information Networking and Security (MINES) 2012;843-846. https://doi.org/ https://doi.org/10.1109/MINES.2012.217.
35. Ma SY, Wang XM. The division of the aged stage and the main points of nursing. J Pract Med Tech. 2008;30:4311-2. https://doi.org/10.3969/j.issn. 1671-5098.2008.30.126

36. Zhou G, Cao W, Deng XH. Gap between the subjective age and the chronological age of senior tourists and its relation to tourist motivation. J Chongqing Norm Univ (Nat Sci). 2016;4:180-6. https://doi.org/10.11721/ cqnuj20160433.

37. Martin K, Tasi W. Social networks and organizations: Beijing:China Renmin University Press; 2007

38. Ayumi K, Shuichi A, Takayoshi O, Megumi T-U, Kei A, Kouko T, et al. Reliability and validity of the Japanese version of the abbreviated lubben social network scale. Nihon Ronen Igakkai Zasshi Japanese Journal of Geriatrics. 2011:48(2):149-57. https://doi.org/10.3143/geriatrics.48.149.

39. Fan WQ. The concept and category of psychological well-being: psychological reflections on well-being. J Soc Sci. 2000;2:56-9.

40. Hansson A, Forsell $Y$, Hochwälder J, Hillerås P. Impact of changes in life circumstances on subjective well-being in an adult population over a 3-year period. Public Health 2008;122(12):1392-1398. https://doi.org/https://doi. org/10.1016/j.puhe.2008.05.020.

41. Pagotto $V$, Bachion MM, da Silveira EA. Self-assessment of health by older Brazilians: systematic review of the literature. Rev Panam Salud Publica 2013; 33(4): 302-310. https://doi.org/https://doi.org/10.1590/S102049892013000400010

42. Maddox GL, Douglass E. Self-assessment of health status: a longitudinal study of selected elderly subjects. J Chronic Dis. 1964;17(5):449-60. https:// doi.org/10.1016/0021-9681(64)90105-5.

43. Sun F. Structural equation model for subjective well-being. Stat Res. 2007; 24(2):27-32. https://doi.org/10.19343/j.cnki.11-1302/c.2007.02.004.

44. Fang FQ, Lv WH. Analysis on the influencing factors of the welfare level of Chinese urban residents: based on Amartya K. Sen's ability method and structural equation model. Management World. 2009;4:17-26. doi:https:// doi.org/10.19744/j.cnki.11-1235/f.2009.04.003

45. Song R. Time, income, leisure and life satisfaction: an empirical study based on SEM model. Finance Trade Econ. 2014;35(6):100-10. https://doi.org/10. 19795/j.cnki.cn11-1166/f.2014.06.010.

\section{Publisher's Note}

Springer Nature remains neutral with regard to jurisdictional claims in published maps and institutional affiliations.

Ready to submit your research? Choose BMC and benefit from:

- fast, convenient online submission

- thorough peer review by experienced researchers in your field

- rapid publication on acceptance

- support for research data, including large and complex data types

- gold Open Access which fosters wider collaboration and increased citations

- maximum visibility for your research: over $100 \mathrm{M}$ website views per year

At $\mathrm{BMC}$, research is always in progress.

Learn more biomedcentral.com/submissions 